\title{
Melatonin treatment of pre-veraison grape berries modifies phenolic components and antioxidant activity of grapes and wine
}

\author{
Jiang-Fei MENG ${ }^{1,2,3 \dagger}$, Yong YU ${ }^{1 \dagger}$, Tian-Ci SHI ${ }^{1 \dagger}$, Yu-Shi FU ${ }^{1}$, Ting $\mathrm{ZHAO}^{1}$, Zhen-Wen ZHANG ${ }^{1,2 *}$
}

\begin{abstract}
A comprehensive investigation was conducted to determine the effects of exogenous melatonin treatment of pre-veraison grapes on phenolic components and antioxidants of grape berries and wine. The results showed an increase in the concentration of cyanin-3-O-glucoside, peonidin derivatives, and two flavanols [namely (+)-catechins and (-)-epicatechins] of grapes, as well as flavonols in both grapes and wine due to the application of melatonin. These compounds are derivatives of the catalysate of flavonoid 3'-hydroxylase (F3'H) in the flavonoid synthesis pathway of plants. It can be inferred that melatonin increased the activity of F'' $\mathrm{H}$ or expression of $V v F 3^{\prime} H$ during grape berry maturation. In addition, two melatonin treatments of pre-veraison grape berries reduced the DPPH radical-scavenging ability and copper ion-reducing power of grapes and wine, whereas one melatonin treatment just reduced those in wine. This study will provide a practical strategy to change the phenolic composition of grapes and wine.
\end{abstract}

Keywords: melatonin; grape; wine; phenolics; antioxidant activity.

Practical Application: This study will facilitate the production of quality wine using melatonin.

\section{Introduction}

Phenolic compounds are some of the most important quality parameters of wine due to their direct influence on some important organoleptic characteristics (i.e. colour, flavour, bitterness, and astringency) (Garrido \& Borges, 2011). Additionally, the phenolics found in wine are also active in biochemical processes and may offer significant antioxidant protection (Duthie et al., 2000). These translate to the fact that chemicals found in wine have the potential to overcome free radicals that are bound and determined to cause cellular damage, which are a root cause of various forms of cancer and cardiovascular diseases (Matés \& Sánchez-Jiménez, 2000).

Thus, increasing the phenolic content of wine has been a major area of interest in viticultural and enological research. The majority of phenolic compounds are grape-derived (Kennedy, 2008). Their composition and content in grape berries depends on the variety of the grapevine and is influenced by climatic and geographical factors, as well as cultural practices such as light, irrigation, temperature, soil, and plant growth regulators (Obreque-Slier et al., 2010). Currently, the use of plant growth regulators, including gibberellin, ethylene, cytokinins, abscisic acid, and salicylic acid is an effective method and is widely applied in grape cultivation.

Melatonin ( $\mathrm{N}$-acetyl-5-methoxytryptamine), a molecule with low molecular weight and an indole-based structure, is ubiquitous in living organisms. Since the first report of melatonin in plants in 1995, melatonin has been identified in many different plants at a wide range of concentrations (from picograms to micrograms per gram of tissue) (Tan et al., 2012). Current evidence suggests that melatonin can protect plants against damage caused by various biotic and abiotic stresses (Tan et al., 2012). The physiological role of melatonin in plants might also involve the regulation of their response to photoperiod (Arnao \& Hernández-Ruiz, 2006), fruit development (Lei et al., 2013), delayed flowering (Kolář et al., 2003), and leaf senescence (Wang et al., 2013). Melatonin also acts as a growth regulator, similar to indole acetic acid (IAA), and may direct the differentiation of cells, tissues, and organs (Arnao \& Hernández-Ruiz, 2007). Previous studies have suggested that the application of exogenous melatonin promoted lateral root regeneration and growth (Arnao \& Hernández-Ruiz, 2007). Recently, Vitalini et al. (2011) identified melatonin in all grape berry tissues (skin, flesh, and seed). At pre-veraison, the highest melatonin content was found in the berry skin, whereas at veraison, the highest levels were in the seed. Furthermore, during ripening, melatonin decreased in the skin and increased in the seed and flesh. As is known to all, phenolics are derived from trans-cinnamic acid, which is formed by deamination of L-phenylalanine, catalyzed by L-phenylalanine ammonia-lyase (PAL, EC 4.3.1.5). The activity of this enzyme is affected by various biotic and abiotic stresses. Previous research on the seeds of Vigna radiate L. seeds indicated that extrogenous melatonin increased the activity of PAL, accompanied by the induced accumulation of total phenolics and increasement of antioxidant capacity (Szafrańska et al., 2014). However, as a 
new phytohormone, the effect of melatonin on the phenolic composition of grape berries and wine remains unclear.

In this study, we investigated the effect of melatonin on the phenolic composition of mature grape berries and wine by spraying an exogenous melatonin solution on grape berries during the pre-veraison period. This study was conducted to provide sufficient experimental evidence for modifying phenolic content due to melatonin treatment in the grape and wine industry.

\section{Materials and methods}

\subsection{Plant material}

The experimental vineyard was located at Yuquanying Farm $\left(38.27^{\circ} \mathrm{N}, 106.06^{\circ} \mathrm{E}\right)$, Ningxia Hui Autonomous Region, China. Fourteen-year-old Merlot grapevines (Vitis vinifera L.), on its own roots, were grown on a flat terroir with well-drained sandy soil on the eastern piedmont of Helan Mountain. Natural rainfall was supplemented with drip irrigation as required. The vines were spaced $0.6 \mathrm{~m}$ within rows and $3.0 \mathrm{~m}$ between rows, and the rows were oriented in a south-north direction. Vines were trained on a vertical single-cordon positioning system with three wires. The vertical shoot-positioned canopies were uniformly managed and trimmed twice manually between bloom and veraison. A mixture of cymoxanil, mancozeb, and carbendazim were used to prevent downy mildew, anthracnose, white rot, and other fungal diseases. No plant diseases occurred during the growing season.

\subsection{Field treatments}

All trial vines were divided into three groups. Bunches were sprayed once (July 5, 2012; MT-1) or twice (July 5 and July 15, 2012; MT-2) to run-off during the pre-veraison period with $100 \mathrm{mg} \mathrm{L}^{-1}$ melatonin in $0.1 \%(\mathrm{v} / \mathrm{v})$ Tween 80 . Control fruits were sprayed with $0.1 \%(\mathrm{v} / \mathrm{v})$ Tween 80 . Veraison of the control fruit was determined to occur on July 20, 2012. The trial was performed in triplicates with controls and melatonin treatments randomized over three adjacent rows. Each replicate consisted of 15 treated vines ( $\sim 400$ bunches) with an untreated vine separating the different treatments.

\subsection{Harvest and vinification}

Grapes were harvested when they reached an average Brix 22 on September 15, 2012. From each replicate, about 150 berries were separated and frozen at $-20^{\circ} \mathrm{C}$ in order to determine grape phenolic components and antioxidant activity. The remaining grapes were destemmed and crushed with a squeezing roller and enological parameters were determined in the musts.

Grapes fruits $(20 \mathrm{~kg}$ for each of the three replicates per treatment) were vinified in $30 \mathrm{~L}$ stainless steel fermentation tanks. $60 \mathrm{mg} / \mathrm{L} \mathrm{SO}_{2}$ and $30 \mathrm{mg} / \mathrm{L}$ of pectinase (Lallzyme Ex, Lallemand, France) were added to the must simultaneously. After maceration for $24 \mathrm{~h}$, the musts were inoculated with the commercial Saccharomyces cerevisiae strain RC212 (Lavlin, France) $(150 \mathrm{mg} / \mathrm{L})$. The must was fermented at a controlled temperature of $25^{\circ} \mathrm{C}$ for about 10 days. Throughout this period, daily mass homogenization was performed to dissolve the cap of the wine.
Temperature and density were also recorded daily to evaluate fermentation arrests. Once fermentation and maceration were complete, solid parts of the grapes was removed from the vats and pressed. The marcs and lees were discarded, and the wine was stabilized and aged for 3 months, the wine was bottled and stored in the dark at $12-15^{\circ} \mathrm{C}$ until analysis.

\subsection{Determination of total phenolics}

A $0.75 \mathrm{~g}$ sample of grape skin dry powder was extracted with ultrasonic device in $15 \mathrm{~mL}$ of acidified methanol solution (1 M HCl in $80 \%$ methanol) in an external water bath at $25{ }^{\circ} \mathrm{C}$ for $30 \mathrm{~min}$. After extraction, the extracts were centrifuged at $8000 \times g$ for $10 \mathrm{~min}$ at $4{ }^{\circ} \mathrm{C}$. The extraction procedure was repeated four times under identical conditions, then, the 4 supernatants were combined and stored at $-20{ }^{\circ} \mathrm{C}$ in the dark until use (Meng et al., 2017).

The total phenolic content (TPC) was estimated using the Folin-Ciocalteu method (Singleton \& Rossi, 1965). The results were expressed as gallic acid equivalents. The total flavonoid content (TFOC) was determined according to the method of Jia et al. (1999) with minor modifications. The results were expressed as rutin equivalents. The total flavanol and flavans content (TFAC) was detected with $p$-DMACA (Li et al., 1996). The results were expressed as (+)-catechin equivalents. The total anthocyanin content (TAC) was estimated using the $\mathrm{pH}$ differential method (Wrolstad, 1976). The TAC were expressed as malvidin-3-glucoside equivalents.

\subsection{HPLC assay for individual non-anthocyanin phenolic compounds}

Preparation and analysis of non-anthocyanin phenolic compounds in grape berries and wine was based on a previous method from Meng et al. (2017). For non-anthocyanin phenolic compounds in grape skins, triplicate samples of the pulverized berry skins of each treatment ( $2.00 \mathrm{~g}$ dry weight) were exhaustively extracted four times with $5 \mathrm{~mL}$ of distilled water and $45 \mathrm{~mL}$ of ethyl acetate in an orbital shaker (SHZ-88A, Taicang Experiment Equipment Factory, Jiangsu, China) for $30 \mathrm{~min}$ at $20^{\circ} \mathrm{C}$ to avoid thermal degradation. Then, these organic phases were combined and evaporated until dry in a rotary evaporator (SENCO-R series; Shanghai Shensheng Biotech Co. Ltd., Shanghai, China) at $35{ }^{\circ} \mathrm{C}$ under vacuum. Subsequently, the dried residuals were re-dissolved in $5 \mathrm{~mL}$ methanol (HPLC grade). The methanol solution was filtered through a $0.45-\mu \mathrm{m}$ organic membrane and analysed by high performance liquid chromatography (HPLC) coupled with a diode array detector (DAD) (LC-2010A, Shimadzu, Japan). For non-anthocyanin phenolic compounds in wine, $100 \mathrm{~mL}$ of a wine sample was diluted with the same volume of distilled water in a $500-\mathrm{mL}$ separatory funnel. The mixture was then extracted three times with $80 \mathrm{~mL}$ ethyl acetate and processed using the same methods for grape berries.

The compounds were eluted using a Hibar RT Lichrospher SB-C18 column $(250 \times 4.0 \mathrm{~mm}, 5 \mu \mathrm{m})$ and detected at $280 \mathrm{~nm}$. The column temperature was set to $30^{\circ} \mathrm{C}$. The mobile phases 
were comprised of two phases, A (water-acetic acid, 98:2 v/v) and $\mathrm{B}$ (acetonitrile). The gradient elution conditions were as follows: 0-20 $\mathrm{min}, 0-5 \% \mathrm{~B} ; 20-35 \mathrm{~min}, 5-15 \% \mathrm{~B}$; 35-50 $\mathrm{min}$, $15-30 \% \mathrm{~B}$; $50-65 \mathrm{~min}, 30 \% \mathrm{~B}$; $65-75 \mathrm{~min}, 30-0 \% \mathrm{~B}$. The flow rate was $1.0 \mathrm{~mL} / \mathrm{min}$, and the injection volume was $10 \mu \mathrm{L}$. Phenolic compounds were identified by comparing their retention times with those of pure standards and by spiking the samples with standard solutions. Quantifications were made using the external standard method.

\subsection{HPLC assay for individual anthocyanin phenolic compounds}

Preparation and analysis of anthocyanin phenolic compounds in grape berries and wine was based on a previous method from Shi et al. (2017). For anthocyanins in grape skins, freeze-dried skins (0.50 g dry weight), in triplicate, were ground, weighed, and placed into a $50 \mathrm{~mL}$ centrifuge tube with $10 \mathrm{~mL}$ solvent (methanol/water/acetic acid, 70:29:1, v/v/v) in an orbital shaker at $300 \mathrm{rpm}$ for $100 \mathrm{~min}$ at $25^{\circ} \mathrm{C}$. After pouring off the supernatant, the precipitate was re-extracted with $10 \mathrm{~mL}$ of the same solvent three times. The supernatant was combined in a $50 \mathrm{~mL}$ centrifuge tube and centrifuged at $8000 \mathrm{rpm}$ for $5 \mathrm{~min}$. Finally, the supernatant was collected and filtered through a $0.45-\mu \mathrm{m}$ organic membrane. The resulting filtrates were used for qualitative and quantitative HPLC-DAD analyses (LC-20A, Shimadzu, Japan). For anthocyanins in wine, $2 \mathrm{~mL}$ of wine was filtered using a $0.45-\mu \mathrm{m}$ organic membrane, and the resulting filtrates were directly used for qualitative and quantitative HPLC-DAD analyses (LC-2010A, Shimadzu, Japan).

The compounds were eluted using a Hibar RT Lichrospher SB-C18 column $(250 \times 4.0 \mathrm{~mm}, 5 \mu \mathrm{m})$ and detected at $520 \mathrm{~nm}$. The column temperature was set to $35^{\circ} \mathrm{C}$. The mobile phases are composed of A (formic acid/acetonitrile/water, 25:100:800 v/v/v) and B (formic acid/acetonitrile/water, 25:500:400 v/v/v) phases. The gradient elution conditions were as follows: $0-45 \mathrm{~min}$, 0-70\% B; 45-50 min, 70\% B; 50-51 min, 70-0\% B; 51-55 min, $0 \% \mathrm{~B}$. The flow rate was $1.0 \mathrm{~mL} / \mathrm{min}$, and the injection volume was $10 \mu \mathrm{L}$. Phenolic compounds were identified by comparing their retention times with those of pure standards and by spiking the samples with standard solutions. Quantifications were made by using the external standard method.

\subsection{Analysis of antioxidant activity}

The free radical-scavenging capacity of DPPH was estimated using the method of Brand-Williams et al. (1995). Briefly, the grape extract (or wine) and DPPH methanolic solution was mixed and kept for $30 \mathrm{~min}$ under lucifugal conditions. The absorbance of the reaction mixture was measured at $517 \mathrm{~nm}$. The results were expressed as trolox equivalents.

The cupric-reducing antioxidant capacity (CUPRAC) was determined based on the method of Apak et al. (2004). Briefly, the grape extract (or wine) was mixed with $\mathrm{CuSO}_{4}$, neocuproine, and distilled water. After $30 \mathrm{~min}$, the absorbance was measured at $450 \mathrm{~nm}$. The results were expressed as trolox equivalents.

\subsection{Statistical analysis}

Statistical analysis was performed on three replications of the same sample using SPSS 17.0 for Windows. A one-way analysis of variance (ANOVA) and Duncan's multiple range test were used to determine significant differences among samples at a significance level of 0.05 .

\section{Results and discussion}

\subsection{Physicochemical parameters of grape berries and wines}

Table 1 shows the conventional analysis of grape berries and wines from the control and melatonin-treatment groups. Regarding grape berries, melatonin treatment had increased the content of titratable acids, had no significant effect on Brix and total sugar. The ethanol content in all wines was $13 \% \pm 0.4(\mathrm{v} / \mathrm{v})$, and the residual sugar was less than $4.0 \mathrm{~g} / \mathrm{L}$. The titratable acidity of all wines was $5.77 \pm 0.34 \mathrm{~g} / \mathrm{L}$, and the volatile acidity was $0.26 \pm 0.1 \mathrm{~g} / \mathrm{L}, \mathrm{pH}$ value was $3.62 \pm 0.11$. These characteristic of dry red wine revealed a good vinification according to the international standards set by the OIV. However, there was higher titratable acidity in melatonin treated grape and its wine compared with the control. We surmise the application of melatonin may delay the degradation of titratable acidity during the maturation of grapes and thus achieved higher concentration of titratable acidity (via mediating the actions of other plant growth regulators), but it still needs further research to confirm this. It will be a direction in our future studies.

\subsection{Effect of melatonin treatment on the phenolic content of grape berries and wine}

As depicted in Table 2, the MT-2 treatment had sharply decreased concentrations of flavonoids, flavanols and anthocyanins in both grape berries and wines, as well as total phenolics in pericarp, but had no significant effect on total phenolics in wine. Likewise, the MT-1 treatment had reduced total flavonoids and flavanols content in wine, which was similar to the MT-2 treatment, but had no significant effect on the polyphenols content of grapes.

Table 1. Effect of melatonin treatment of pre-veraison grape berries on the physicochemical parameters of grape berries and wine.

\begin{tabular}{lccc}
\hline \multicolumn{1}{c}{ Parameter } & Control & MT-1 & MT-2 \\
\hline Grape berries & & & \\
Brix & $20.2 \pm 0.6^{\mathrm{a}}$ & $21.0 \pm 0.4^{\mathrm{a}}$ & $20.7 \pm 0.3^{\mathrm{a}}$ \\
Total sugar & $198 \pm 4^{\mathrm{a}}$ & $203 \pm 3^{\mathrm{a}}$ & $201 \pm 4^{\mathrm{a}}$ \\
Titratable acids & $7.7 \pm 0.3^{\mathrm{b}}$ & $8.0 \pm 0.1^{\mathrm{ab}}$ & $8.1 \pm 0.2^{\mathrm{a}}$ \\
pH value & $3.0 \pm 0.1^{\mathrm{a}}$ & $3.0 \pm 0.2^{\mathrm{a}}$ & $3.0 \pm 0.1^{\mathrm{a}}$ \\
Wines & & & \\
Alcohol (\%) & $13.0 \pm 0.1^{\mathrm{a}}$ & $13.2 \pm 0.2^{\mathrm{a}}$ & $13.1 \pm 0.2^{\mathrm{a}}$ \\
Residual sugar & $3.3 \pm 0.1^{\mathrm{a}}$ & $3.3 \pm 0.1^{\mathrm{a}}$ & $3.0 \pm 0.1^{\mathrm{b}}$ \\
Titratable acids & $5.4 \pm 0.3^{\mathrm{b}}$ & $6.0 \pm 0.3^{\mathrm{a}}$ & $6.0 \pm 0.3^{\mathrm{a}}$ \\
pH value & $3.7 \pm 0.0^{\mathrm{a}}$ & $3.5 \pm 0.0^{\mathrm{b}}$ & $3.6 \pm 0.0^{\mathrm{b}}$ \\
Volatile acids & $0.3 \pm 0.0^{\mathrm{a}}$ & $0.2 \pm 0.0^{\mathrm{c}}$ & $0.3 \pm 0.0^{\mathrm{b}}$ \\
\hline
\end{tabular}

Values are expressed as means of triplicate determinations $(n=3) \pm$ standard deviation. Residual sugar, titratable acids, and volatile acidities are expressed in g/L glucose, g/L tartaric acid, and $\mathrm{g} / \mathrm{L}$ acetic acid, respectively. Different letters $(\mathrm{a}-\mathrm{c})$ within rows indicate significant differences at $\mathrm{p}<0.05$ by Duncan's test. 
Table 2. Effect of melatonin treatment of pre-veraison grape berries on the phenolic composition and antioxidant activity of grape berries and wine.

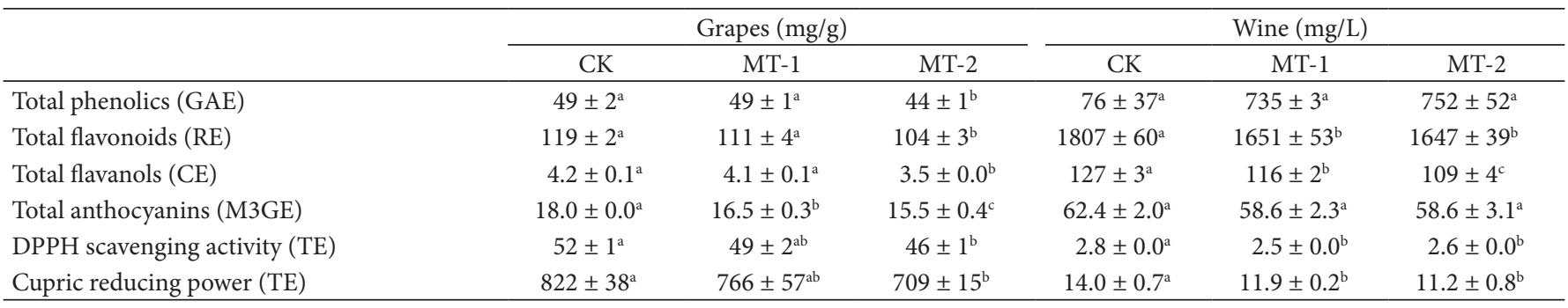

Note: GAE, RE, CE and M3GE represent gallic acid equivalents, rutin equivalents, (+)-catechin equivalents, and malvidin-3-glucoside equivalents, respectively. TE represents trolox equivalents for DPPH free radical-scavenging capacity and cupric-reducing antioxidant capacity. Values are means of triplicate determinations ( $\mathrm{n}=3$ ) \pm standard deviation. Different letters $(\mathrm{a}-\mathrm{c})$ within rows indicate significant differences at $p<0.05$ by Duncan's test.

The results was inconsistent with previous studies on bitter orange leaves, which showed that $15 \mu \mathrm{M}$ melatonin increased the total leaf phenolics and flavonoids content of leaf methanolic extracts (Sarrou et al., 2015). Such difference may due to the degree of sensitivity to exogenous melatonin result from varietal differences and different issues of a plant. Phenolics accumulation in plants is closely related to environmental stress. As an important antioxidant, melatonin can scavenge excess free radical and protect plants against environmental stress (Posmyk \& Janas, 2009). In our study, the low concentration of total phenolics and flavonoids in the grape berries and wines of melatonin treatment group could be connected with the application of melatonin reducing the grape damage from environmental stress.

\subsection{Effect of melatonin treatment on the antioxidant activity of grape berries and wine}

Table 2 also shows the effect of melatonin treatment during the pre-veraison period on grape and wine antioxidant activity. Both melatonin treatments reduced the antioxidant activity of grapes and wine. Compared with the control, the DPPH-scavenging and copper ion-reducing power was not significant for MT-1-treated grapes, but significantly decreased in MT-2-treated grapes, with the indices declining by $12.7 \%$ and $13.7 \%$, respectively. For wine, both melatonin treatments significantly decreased them as compared to control. Such decrease in antioxidant activities may due to the decline of antioxidant active components contents (i.e. total phenolics, total flavonoids and total flavanols) of grapes and wine result from the exogenous melatonin applied. With respect to the same variation pattern between phenolic content and the responding antioxidant properties, Vitalini et al. (2011) reported that grapes with a higher level of phenolic compounds demonstrated considerably antioxidant resistence in their counterparts. This finding is also in accordance with the results reported by Sarrou et al. (2015), which showed that leaf extracts treated with the PGRs resulted in high phenolic and flavonoid content accompanied by the increased DPPH antioxidant activity. In all, both studies mentioned-above observed the closely relationship between phenolics contents and their antioxidant activity presenting.

\subsection{Effect of melatonin treatment on individual non-anthocyanin phenolic compounds in grape and wine}

In the present study, we analysed a total of 17 types of non-anthocyanin phenolic compounds in grape skins and wine. As shown in Table 3, flavan-3-ols were still the most abundant non-anthocyanin phenolic compounds in grapes and wine, which play an important role in the taste of grapes and wine mouthfeel sensations and colour stability. Regarding to flavan-3-ols, both MT-1 and MT-2 treatment groups presented significantly higher concentrations in pericarps compared with the control, but exhibited dramatically lower concentrations in their respective wines when compared to the control. Furthermore, the (-)-epicatechin content ranked first in all non-anthocyanin phenolic compounds detected, followed by $(+)$-catechin. Compared with the control, the contents of both $(+)$-catechin and (-)-epicatechin increased in grape pericarps, but decreased in their corresponding wines, which was consistent with that of flavanols. Both compounds are important flavanol monomers present in grapes and wine, and via polymerization they form other flavanol oligomers and polymers (i.e., condensed tannins or proanthocyanidins), which play a prominent role in the taste of wine (mainly bitterness, astringency, and taste) due to differences in the degree of polymerization (Wang, 2008). Our study showed significantly higher contents of $(+)$-catechin and (-)-epicatechin in grapes treated with melatonin and in comparison with non-treated grapes.

Flavonol is another important grape and wine flavonoid compound, which contributes to the colour of flowers, fruits, and fruit products along with anthocyanins (Obreque-Slier et al., 2010). As presented in Table 3, unlike flavan-3-ols, though flavonols in grapes and wines responded to the melatonin treatments with dramatically higher contents compared to the control, these compounds increased to a larger extent in the MT-2 treatment. Wine flavonols are mainly derived from grape skins, and are transferred from the grape into the wine during winemaking operations. The result that melatonin facilitated the accumulation of flavonols in grapes may because it accelerated the expression or activity of flavonol synthase genes during its synthesis, but it still needs more evidence to confirm this deduction. Of all the flavonols detected in grapes and wine, rutin made up the largest proportion. Its content in the grape pericarp was $88.55 \mu \mathrm{g} / \mathrm{g}$ for the control group, whereas in the MT-1 and MT-2 treatment groups, it increased to 149.29 and $200.96 \mu \mathrm{g} / \mathrm{g}$, respectively, which is 1.7 - and 2.3-fold that of the control group. A similar pattern was observed for the content of rutin in wine. In addition, morin and quercetin are two additional flavonols with higher content in grapes and wine. The content of morin in the grape pericarp was $40.72 \mu \mathrm{g} / \mathrm{g}$ in the control group, but in the MT-1 and MT-2 treatment groups 
Meng et al.

Table 3. Effect of melatonin treatment of pre-veraison grape berries on individual non-anthocyanin phenolic compounds of grape berries and wine.

\begin{tabular}{|c|c|c|c|c|c|c|}
\hline & \multicolumn{3}{|c|}{ Grapes $(\mu \mathrm{g} / \mathrm{g})$} & \multicolumn{3}{|c|}{ Wine $(\mathrm{mg} / \mathrm{L})$} \\
\hline & CK & MT-1 & MT-2 & CK & MT-1 & MT-2 \\
\hline \multicolumn{7}{|l|}{ Flavan-3-ols } \\
\hline (-)-Epicatechin & $361 \pm 23^{c}$ & $453 \pm 30^{\mathrm{b}}$ & $613 \pm 40^{\mathrm{a}}$ & $18 \pm 1^{\mathrm{a}}$ & $17 \pm 1^{\mathrm{ab}}$ & $15 \pm 1^{\mathrm{b}}$ \\
\hline Sum of flavan-3-ols & $527.4(64.4 \%)$ & $697.5(62.8 \%)$ & $815.7(60.2 \%)$ & $34.1(43.5 \%)$ & $32.6(43.2 \%)$ & $29.2(39.3 \%)$ \\
\hline \multicolumn{7}{|l|}{ Flavonols } \\
\hline Kaempferol & $3.4 \pm 0.2^{\mathrm{a}}$ & $3.2 \pm 0.2^{\mathrm{a}}$ & $1.9 \pm 0.1^{\mathrm{b}}$ & $0.1 \pm 0.0^{c}$ & $0.3 \pm 0.0^{\mathrm{b}}$ & $0.9 \pm 0.0^{\mathrm{a}}$ \\
\hline Morin & $41 \pm 3^{\mathrm{b}}$ & $57 \pm 3^{\mathrm{a}}$ & $52 \pm 4^{\mathrm{a}}$ & $1.8 \pm 0.1^{\mathrm{a}}$ & $1.6 \pm 0.1^{\mathrm{b}}$ & $1.8 \pm 0.2^{\mathrm{a}}$ \\
\hline Hesperetin & $0.9 \pm 0.0^{\mathrm{a}}$ & $0.9 \pm 0.0^{\mathrm{a}}$ & $0.9 \pm 0.0^{\mathrm{a}}$ & $0.1 \pm 0.0^{c}$ & $0.2 \pm 0.0^{\mathrm{b}}$ & $0.5 \pm 0.0^{\mathrm{a}}$ \\
\hline Sum of flavonols & $145.5(17.8 \%)$ & $224.0(20.2 \%)$ & $267.2(19.7 \%)$ & $5.7(7.2 \%)$ & $7.4(9.8 \%)$ & $9.5(12.8 \%)$ \\
\hline \multicolumn{7}{|l|}{ Hydroxybenzoic acids } \\
\hline Sum of hydroxybenzoic acids & $52.2(6.4 \%)$ & $64.1(5.8 \%)$ & $98.8(7.3 \%)$ & $30.5(38.9 \%)$ & $27.7(36.7 \%)$ & $27.7(37.3 \%)$ \\
\hline \multicolumn{7}{|l|}{ Hydroxycinnamic acids } \\
\hline Chlorogenic acid & $22 \pm 1^{\mathrm{b}}$ & $24 \pm 1^{\mathrm{b}}$ & $36 \pm 1^{\mathrm{a}}$ & $0.6 \pm 0.0^{c}$ & $0.7 \pm 0.0^{\mathrm{b}}$ & $0.9 \pm 0.1^{\mathrm{a}}$ \\
\hline Caffeic acid & $5.3 \pm 0.3^{\mathrm{c}}$ & $20 \pm 1^{\mathrm{b}}$ & $23 \pm 1^{\mathrm{a}}$ & $2.3 \pm 0.2^{\mathrm{a}}$ & $1.6 \pm 0.1^{\mathrm{b}}$ & $1.8 \pm 0.1^{\mathrm{b}}$ \\
\hline Cumaric acid & $6.1 \pm 0.2$ & n.d. & n.d. & $1.5 \pm 0.1^{\mathrm{a}}$ & $1.5 \pm 0.1^{\mathrm{a}}$ & $1.0 \pm 0.1^{\mathrm{b}}$ \\
\hline Ferulic acid & n.d. & n.d. & $5.7 \pm 0.3$ & n.d. & n.d. & n.d. \\
\hline Coumarin & $53 \pm 4^{c}$ & $68 \pm 4^{\mathrm{b}}$ & $101 \pm 9^{\mathrm{a}}$ & $1.3 \pm 0.1^{\mathrm{b}}$ & $1.20 \pm 0.09^{\mathrm{b}}$ & $1.4 \pm 0.1^{\mathrm{a}}$ \\
\hline $\begin{array}{l}\text { Sum of hydroxycinnamic } \\
\text { acids }\end{array}$ & $86.8(10.6 \%)$ & $112.0(10.1 \%)$ & $165.8(13.2 \%)$ & $5.6(7.2 \%)$ & $5.0(6.6 \%)$ & $5.1(6.9 \%)$ \\
\hline \multicolumn{7}{|l|}{ Stilbenes } \\
\hline
\end{tabular}

Note: Different letters $(\mathrm{a}-\mathrm{c})$ within rows indicate significant differences according to Duncan's multiple range test $(p<0.05)$. n.d. $=$ not detected.

it increased to 57.39 and $52.38 \mu \mathrm{g} / \mathrm{g}$, respectively; however, its content in wine showed no significant difference between the MT-2 treatment and the control group, whereas notably decreased in MT-1 treatment in contrast with the control. For quercetin, both melatonin treatments had minor effect on pericarp quercetin content, but its content significantly increased in wine compared with the control, with the content in MT-2-treated wine significantly higher than MT-1-treated wine.

Hydroxybenzoic and hydroxycinnamic acids are two important non-flavonoid compounds in grapes and wine, but melatonin treatment did not evidently change their content in grape and wine. The other familiar grape derived non-flavonoid class is the stilbene. Although stilbenes are found in trace quantities in grapes and wine, they have drawn attention because of their purported anti-carcinogenic properties (Conde et al., 2007). The most famous of the stilbenes is resveratrol. In this study, resveratrol was the only stilbene compound analysed, and both melatonin treatments showed a significant increase in the resveratrol content of grapes and a minor increasement in wines.

\subsection{Effect of melatonin treatment on individual anthocyanin phenolic compounds in grape and wine}

Anthocyanins are located in the berry skin, and as the main flavonoids, they responsible for the red colour of grapes and wines (Núñez et al., 2004). The influence of melatonin treatment on the monomeric anthocyanin content of grapes and wine is shown in Table 4. In this study, a total of 9 monomeric anthocyanin compounds were quantified both in grape pericarps and wine. The anthocyanin profile under this study was mainly formed by the related monoglucosides and acylated with either acetic, or $p$-coumaric from the five anthocyanidin structures (Lingua et al., 2016). As can be seen in Table 4, malvidin derivatives presented the highest concentration among all anthocyanins detected in grapes and wines, being malvidin-3-O-glucoside the main anthocyanins, which was consistent with many authors (Portu et al., 2016; Lingua et al., 2016). This is because malvidin is the terminal anthocyanidin in biosynthesis of anthocyanins (Núñez et al., 2004). To the best of our knowledge, wine anthocyanins are divided into acylated anthocyanins and non-acylated anthocyanins in accordance with their acylated forms. In this study, the total concentrations of the five non-acylated anthocyanins were significantly higher than 
Table 4. Effect of melatonin treatment of pre-veraison grape berries on individual anthocyanins of grape berries and wine.

\begin{tabular}{|c|c|c|c|c|c|c|}
\hline \multirow{2}{*}{ Anthocyanins } & \multicolumn{3}{|c|}{ Grapes $(\mu \mathrm{g} / \mathrm{g})$} & \multicolumn{3}{|c|}{ Wine $(\mathrm{mg} / \mathrm{L})$} \\
\hline & $\mathrm{CK}$ & MT-1 & MT-2 & CK & MT-1 & MT-2 \\
\hline Delphinidin 3-O-glucoside & $177.0 \pm 0.0^{\mathrm{a}}$ & $166.5 \pm 0.2^{\mathrm{b}}$ & $165 \pm 2^{\mathrm{b}}$ & $1.3 \pm 0.0^{\mathrm{a}}$ & $1.6 \pm 0.3^{\mathrm{a}}$ & $0.9 \pm 0.0^{b}$ \\
\hline Cyanidin-3-O-glucoside & $45.2 \pm 0.0^{\mathrm{b}}$ & $41.8 \pm 0.0^{c}$ & $46.8 \pm 0.4^{\mathrm{a}}$ & $0.8 \pm 0.0^{\mathrm{a}}$ & $0.8 \pm 0.1^{\mathrm{a}}$ & $0.5 \pm 0.0^{\mathrm{b}}$ \\
\hline Petunidin-3-O-glucoside & $171.6 \pm 0.2^{\mathrm{a}}$ & $147.1 \pm 0.1^{\mathrm{c}}$ & $161.4 \pm 0.9^{\mathrm{b}}$ & $2.6 \pm 0.0^{\mathrm{a}}$ & $2.8 \pm 0.2^{\mathrm{a}}$ & $1.9 \pm 0.1^{\mathrm{b}}$ \\
\hline Peonidin-3-O-glucoside & $244.8 \pm 0.2^{\mathrm{b}}$ & $201.1 \pm 0.6^{c}$ & $292 \pm 2^{\mathrm{a}}$ & $1.3 \pm 0.1^{\mathrm{a}}$ & $1.5 \pm 0.3^{\mathrm{a}}$ & $1.1 \pm 0.0^{\mathrm{a}}$ \\
\hline Malvidin-3-O-glucoside & $1065.5 \pm 0.6^{\mathrm{a}}$ & $993 \pm 3^{b}$ & $925 \pm 5^{c}$ & $31.5 \pm 0.5^{\mathrm{a}}$ & $35 \pm 3^{\mathrm{a}}$ & $22.3 \pm 0.6^{\mathrm{b}}$ \\
\hline Peonidin-3-O-(6-O-acetal)-glucoside & $81.7 \pm 0.4^{\mathrm{b}}$ & $76.9 \pm 0.5^{c}$ & $102 \pm 1^{\mathrm{a}}$ & $2.1 \pm 0.5^{\mathrm{a}}$ & $2.0 \pm 0.4^{\mathrm{a}}$ & $1.6 \pm 0.2^{\mathrm{b}}$ \\
\hline Malvidin-3-O-(6-O-acetal)-glucoside & $602 \pm 4^{\mathrm{a}}$ & $610 \pm 7^{\mathrm{a}}$ & $531 \pm 9^{b}$ & $10.7 \pm 0.8^{\mathrm{a}}$ & $12.3 \pm 1.2^{\mathrm{a}}$ & $8.4 \pm 0.4^{\mathrm{b}}$ \\
\hline Peonidin 3-O-(6-O-coumaryl)-glucoside & $94 \pm 5^{c}$ & $77 \pm 9^{\mathrm{b}}$ & $108 \pm 10^{\mathrm{a}}$ & $2.2 \pm 0.1^{\mathrm{a}}$ & $1.8 \pm 0.3^{\mathrm{b}}$ & $1.6 \pm 0.1^{\mathrm{b}}$ \\
\hline Malvidin 3-O-(6-O-coumaryl)-glucoside & $409 \pm 17^{\mathrm{a}}$ & $364 \pm 33^{\mathrm{ab}}$ & $293 \pm 22^{b}$ & $1.7 \pm 0.2^{\mathrm{a}}$ & $2.2 \pm 0.8^{\mathrm{a}}$ & $1.6 \pm 0.3^{\mathrm{a}}$ \\
\hline Sum of anthocyanins & 2890.2 & 2677.7 & 2622.7 & 54.3 & 59.7 & 39.8 \\
\hline
\end{tabular}

Note: Different letters (a-c) within rows indicate significant differences according to Duncan's multiple range test $(p<0.05)$.

those of the four acylated anthocyanins in all groups, which was in agreement with previous findings (Ruiz-García et al., 2012), whether or not sprayed with melatonin. In addition, both grapes and wine demonstrated a lower degree of acetylation of anthocyanins, with acetylation and coumadin acetylation being dominant. In all, the MT-1 treatment only slightly facilitated the accumulation of malvidin-3-O-(6-O-acetal)-glucoside in grapes, but had little to no influence on the accumulation of other anthocyanins and no significant effect on the content of most anthocyanins in wine. The MT-2 treatment only slightly stimulated the accumulation of cyanidin-3-O-glucoside, and peonidin derivatives of anthocyanins [peonidin-3-O-glucoside, peonidin-3-O-(6-O-acetyl)-glucoside and peonidin 3-O-(6-O-coumaryl)-glucoside] in grapes, but reduced the content of most anthocyanins in wine.

In any case, anthocyanins play a vital part in the colour of red grapes and wine. As wine colour is the first feature perceived by the consumer, thus has a substantial impact on the final wine quality. Our study showed that MT-1 and MT-2 treatment promoted the accumulation of some particular anthocyanins in grapes but decreased the total amount of anthocyanins in grapes and MT-2-treated wine. Taking into account the fact that anthocyanins and flavonols share most of their biosythetic pathway, with anthocyanin metabolism preferentially activated compared to flavonol's, thus it should be recognized that flavonols are important copigments that contribute to 4 wine colour stability (Schwarz et al., 2005). The higher level of flavonols result from the application of melatonin showed in Table 4 may make up for the deficiency of anthocyanin's lower one to some extent.

Besides, the results showed lower total anthocyanin content in melatonin treated grapes compared to the control. A recent study from Li et al. (2015) showed that melatonin treatment significantly up-regulated abscisic acid (ABA) catabolism genes and down-regulated ABA biosynthesis genes in cucumber and apple, respectively, resulting in a rapid decrease of $A B A$ content. As is known to us, lower abscisic acid (ABA) content can result in delaying the ripening process of grapes and thus prevent the normal accumulation of anthocyanin content. In our study, we inferred the application of melatonin led to lower level of ABA, and thus achieved lower content of total anthocyanin.

Figure 1 showed the melatonin levels in different treated grape berries. It is obvious that very significant differences existed

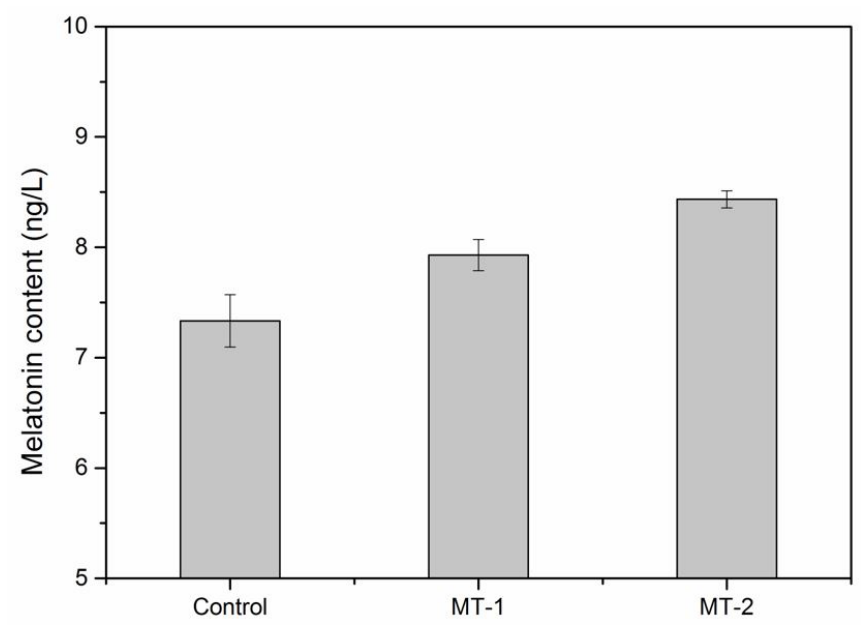

Figure 1. Comparison of melatonin content between control and melatonin-treated berries.

either between the control and the melatonin treated groups or between both melatonin treatments, with the MT-2 treated grape berries presented the highest concentration of melatonin. The melatonin content of MT- 1 and MT- 2 treated grape berries was 7.93 and $8.44 \mathrm{ng} / \mathrm{L}$ repectively, increasing the content by $8.2 \%$ and $15.1 \%$ as compared with the control. The increasement in melatonin content probably due to exogenous melatonin applied was consistent with earlier reports on the roots of Vigna radiata seedlings (Szafrańska et al., 2014), which indicated that melatonin applied to the seeds of $V$. radiata can improve the melatonin content. So we can infer that the exogenous melatonin applied to pre-veraison berries stimulated the concentration of melatonin in grape berries.

Based on the synthetic pathway of phenolic compounds presented in Figure 2, a prevalent synthetic pathway with increased contents was observed in melatonin-treated groups (including anthocyanin derivatives in anthocyanins, and also flavonols such as rutin, catechins and epicatechins), all of which are metabolites of eriodictyol. In the plant flavonoid metabolic pathway, naringenin can be transferred to eriodictyol and pentahydroxyflavanone with flavonoid 3'-hydroxylase (F3'H) and flavonoid 3',5'-hydroxylase (F3'5'H), respectively. Of these 


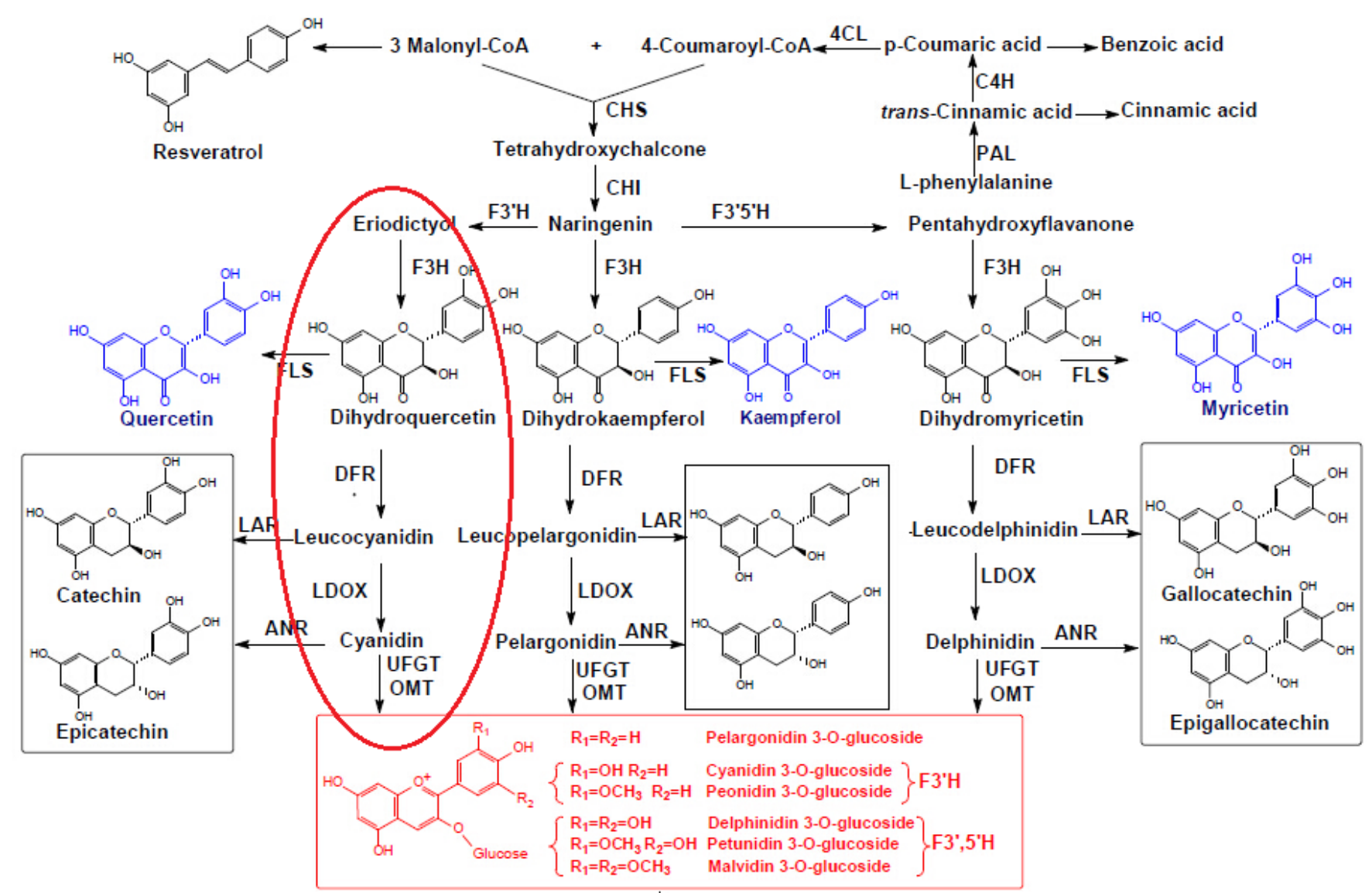

Figure 2. Biosynthetic pathway of phenolic compounds in grape berries (He, 2010).

two substances, eriodictyol can be transformed thru the catalysis of other enzymes into anthocyanin derivatives, such as rutin, catechin, epicatechin, and other substances, whereas naringenin and pentahydroxyflavanone generate other flavonoids using related enzymes. Hence, it can be inferred that melatonin can promote an increase in activity or expression of F3'H genes, thereby increasing the content of anthocyanin derivatives, such as rutin, catechin, epicatechin, and other related substances in grape berries.

\section{Conclusions}

In summary, application of melatonin to grape berries during the pre-veraison period can induce the biosynthesis of eriodictyol metabolic constituents, such as cyaniding derivatives, rutin, catechin, epicatechin, and other related substances in grape berries, and reduce the antioxidant activity of grape berry and wine. From a practical standpoint, this study was carried out to provide sufficient experimental evidence for adjusting wine colour and flavour, and making fresh wine by means of improving cultivation practice and application of growth regulators. In addition, high melatonin content in the grape berries of the melatonin treated groups could also contribute to tolerance to some biotic and abiotic stresses during grape growth and development and decrease use frequency of fungicide and pesticide.

\section{Acknowledgements}

This work was supported by the Scientific Research Start-up Funds of Northwest A\&F University (2452015309); the Fundamental Research Funds for the Central Universities (2452016089); and the China Agriculture Research System for Grape (CARS-29).

\section{References}

Apak, R., Güçlü, K., Ozyürek, M., \& Karademir, S. E. (2004). Novel total antioxidant capacity index for dietary polyphenols and vitamins $\mathrm{C}$ and $\mathrm{E}$, using their cupric iron reducing capability in the presence of neocuproine: CUPRAC method. Journal of Agricultural and Food Chemistry, 52(26), 7970-7981. PMid:15612784. http://dx.doi. $\operatorname{org} / 10.1021 /$ jf048741x.

Arnao, M. B., \& Hernández-Ruiz, J. (2006). The physiological function of melatonin in plants. Plant Signaling \& Behavior, 1(3), 89-95. PMid:19521488. http://dx.doi.org/10.4161/psb.1.3.2640.

Arnao, M. B., \& Hernández-Ruiz, J. (2007). Melatonin promotes adventitious-and lateral root regeneration in etiolated hypocotyls of Lupinus albus L. Journal of Pineal Research, 42(2), 147-152. PMid:17286746. http://dx.doi.org/10.1111/j.1600-079X.2006.00396.x.

Brand-Williams, W., Cuvelier, M. E., \& Berset, C. (1995). Use of a free-radical method to evaluate antioxidant activity. LebensmittelWissenschaft + Technologie, 28(1), 25-30. http://dx.doi.org/10.1016/ S0023-6438(95)80008-5. 
Conde, C., Silva, P., Fontes, N., Dias, A. C. P., Tavares, R. M., Sousa, M. J., Agasse, A., Delrot, S., \& Gerós, H. (2007). Biochemical changes throughout grape berry development and fruit and wine quality. Food, 1(1), 1-22.

Duthie, G. G., Duthie, S. J., \& Kyle, J. A. M. (2000). Plant polyphenols in cancer and heart disease: implications as nutritional antioxidants. Nutrition Research Reviews, 13(1), 79-106. PMid:19087434. http:// dx.doi.org/10.1079/095442200108729016.

Garrido, J., \& Borges, F. (2011). Wine and grape polyphenols-A chemical perspective. Food Research International, 44(10), 3134-3148. http:// dx.doi.org/10.1016/j.foodres.2011.08.010.

He, J. J. (2010). Analysis on factors of affecting anthocyanin modification in wine grapes (Vitis vinifera L.) (DPhil dissertation). China Agricultural University, Beijing.

Jia, Z. S., Tang, M. C., \& Wu, J. M. (1999). The determination of flavonoid contents in mulberry and their scavenging effects on superoxide radicals. Food Chemistry, 64(4), 555-559. http://dx.doi.org/10.1016/ S0308-8146(98)00102-2 .

Kennedy, J. A. (2008). Grape and wine phenolics: observations and recent findings. Ciencia e Investigación Agraria, 35(2), 107-120. http://dx.doi.org/10.4067/S0718-16202008000200001.

Kolář, J., Johnson, C. H., \& Machackova, I. (2003). Exogenously applied melatonin (N-acetyl-5-methoxytryptamine) affects flowering of the short-day plant Chenopodium rubrum. Physiologia Plantarum, 118(4), 605-612. http://dx.doi.org/10.1034/j.1399-3054.2003.00114.x.

Lei, Q., Wang, L., Tan, D. X., Zhao, Y., Zheng, X. D., Chen, H., Li, Q. T., Zuo, B. X., \& Kong, J. (2013). Identification of genes for melatonin synthetic enzymes in 'Red Fuji' apple (Malus domestica Borkh. $\mathrm{cv}$. Red) and their expression and melatonin production during fruit development. Journal of Pineal Research, 55(4), 443-451. PMid:24102635.

Li, C., Tan, D. X., Liang, D., Chang, C., Jia, D. F., \& Ma, F. W. (2015). Melatonin mediates the regulation of ABA metabolism, free-radical scavenging, and stomatal behaviour in two Malus species under drought stress. Journal of Experimental Botany, 66(3), 669-680. PMid:25481689. http://dx.doi.org/10.1093/jxb/eru476.

Li, Y. G., Tanner, G., \& Larkin, P. (1996). The DMACA-HCl protocol and the threshold proanthocyanidin content for bloat safety in forage legumes. Journal of the Science of Food and Agriculture, 70(1), 89-101. http://dx.doi.org/10.1002/(SICI)1097-0010(199601)70:1<89::AIDJSFA470>3.0.CO;2-N.

Lingua, M. S., Fabani, M. P., Wunderlin, D. A., \& Baroni, M. V. (2016). From grape to wine: changes in phenolic composition and its influence on antioxidant activity. Food Chemistry, 208, 228-238. PMid:27132844. http://dx.doi.org/10.1016/j.foodchem.2016.04.009.

Matés, J. M., \& Sánchez-Jiménez, F. M. (2000). Role of reactive oxygen species in apoptosis: implications for cancer therapy. The International Journal of Biochemistry \& Cell Biology, 32(2), 157-170. PMid:10687951. http://dx.doi.org/10.1016/S1357-2725(99)00088-6.

Meng, J.-F., Shi, T.-C., Yu, Y., Zuo, L.-L., Fu, Y.-S., Wang, Q., \& Zhang, Z.-W. (2017). Fruit sphere microenvironments and berry phenolic content of Cabernet Sauvignon (Vitis vinifera L.) cultivated under rain-shelter systems with coloured plastic film. Food Science and Technology, 37(4), 585-592. http://dx.doi.org/10.1590/1678-457x.25516.

Núñez, V., Monagas, M., Gomez-Cordovés, M. C., \& Bartolomé, B. (2004). Vitis vinifera L. cv. Graciano grapes characterized by its anthocyanin profile. Postharvest Biology and Technology, 31(1), 69-79. http://dx.doi.org/10.1016/S0925-5214(03)00140-6.
Obreque-Slier, E., Peña-Neira, Á., López-Solís, R., Zamora-Marín, F., Ricardo-da Silva, J. M., \& Laureano, O. (2010). Comparative study of the phenolic composition of seeds and skins from Carménère and Cabernet Sauvignon grape varieties (Vitis vinifera L.) during ripening. Journal of Agricultural and Food Chemistry, 58(6), 35913599. PMid:20163111. http://dx.doi.org/10.1021/jf904314u.

Portu, J., López, R., Baroja, E., Santamaría, P., \& Garde-Cerdán, T. (2016). Improvement of grape and wine phenolic content by foliar application to grapevine of three different elicitors: methyl jasmonate, chitosan, and yeast extract. Food Chemistry, 201, 213-221. PMid:26868568. http://dx.doi.org/10.1016/j.foodchem.2016.01.086.

Posmyk, M. M., \& Janas, K. M. (2009). Melatonin in plants. Acta Physiologiae Plantarum, 1(1), 1-7. http://dx.doi.org/10.1007/ s11738-008-0213-z.

Ruiz-García, Y., Romero-Cascales, I., Gil-Muñoz, R., FernandezFernandez, J. L., Lopez-Roca, J. M., \& Gomez-Plaza, E. (2012). Improving grape phenolic content and wine chromatic characteristics through the use of two different elicitors: methyl jasmonate versus benzothiadiazole. Journal of Agricultural and Food Chemistry, 60(5), 1283-1290. http://dx.doi.org/ 10.1021/jf204028d .

Sarrou, E., Chatzopoulou, P., Dimassi-Theriou, K., Therios, I., \& Koularmani, A. (2015). Effect of melatonin, salicylic acid and gibberellic acid on leaf essential oil and other secondary metabolites of bitter orange young seedlings. The Journal of Essential Oil Research, 27(6), 487-496. http://dx.doi.org/10.1080/10412905.2015.1064485.

Schwarz, M., Picazo-Bacete, J. J., Winterhalter, P., \& Hermosín-Gutiérrez, I. (2005). Effect of copigments and grape cultivar on the colour of red wines fermented after the addition of copigments. Journal of Agricultural and Food Chemistry, 53(21), 8372-8381. PMid:16218690. http://dx.doi.org/10.1021/jf051005o.

Shi, P., Zuo, L., Liu, M., Song, C., Zhang, Z., \& Meng, J. (2017). Berry anthocyanin content of Cabernet Sauvignon (Vitis vinifera L.) cultivated under rain-shelter systems with different coloured plastic films. The Journal of Horticultural Science \& Biotechnology, 1-11. http://dx.doi.org/10.1080/14620316.2017.1343102.

Singleton, V. L., \& Rossi, J. A. (1965). colourimetry of total phenols with phosphomolybdic phosphotungstic acid reagents. American Journal of Enology and Viticulture, 16, 144-158.

Szafrańska, K., Szewczyk, R., \& Janas, K. M. (2014). Involvement of melatonin applied to Vigna radiate L. seeds in plant response to chilling stress. Central European Journal of Biology, 9(11), 1117-1126.

Tan, D. X., Hardeland, R., Manchester, L. C., Korkmaz, A., Ma, S., Rosales-Corral, S., \& Reiter, R. J. (2012). Functional roles of melatonin in plants, and perspectives in nutritional and agricultural science. Journal of Experimental Botany, 63(2), 577-597. PMid:22016420. http://dx.doi.org/10.1093/jxb/err256.

Vitalini, S., Gardana, C., Zanzotto, A., Simonetti, P., Faoro, F., Fico, G., \& Iriti, M. (2011). The presence of melatonin in grapevine (Vitis vinifera L.) berry tissues. Journal of Pineal Research, 51(3), 331-337. PMid:21615489. http://dx.doi.org/10.1111/j.1600-079X.2011.00893.x.

Wang, P., Sun, X., Li, C., Wei, Z. W., Liang, D., \& Ma, F. W. (2013). Longterm exogenous application of melatonin delays drought-induced leaf senescence in apple. Journal of Pineal Research, 54(3), 292-302. PMid:23106234. http://dx.doi.org/10.1111/jpi.12017.

Wang, X. Y. (2008). Study on the antioxidant activity and methods of detection in wine (DPhil dissertation). Northwest A\&F University, Yangling, Shaanxi, China.

Wrolstad, R. E. (1976). Colour and pigment analyses in fruit products. Corvallis: Oregon Agricultural Experimental Statio. 